\title{
Model for Measuring Passenger Satisfaction and Assessing Mass Transit Quality
}

\author{
Ivana Olivková, Ph.D. \\ VŠB - Technical University of Ostrava
}

\begin{abstract}
This paper presents a detailed description and explanation of the model for measuring passenger satisfaction and assessing the quality of mass transit. The basis of this model is the assessment of a mixed set of mass transit quality criteria, both quantitative and qualitative in nature. The model was applied in an actual case study of the mass transit system in Ostrava as an assessment of transportation passenger satisfaction. The paper presents the results of the model's application and includes an analysis of the results of the survey using SWOT analysis. The conclusion assesses the benefits and practical application possibilities of the model for measuring passenger satisfaction and mass transit quality. Some of the primary advantages of the model include the option of presenting basic survey results. In combining the values of satisfaction and importance for the individual criteria or groups thereof, it is possible to formulate conclusions on the necessity of further actions by the carrier.
\end{abstract}

\section{Introduction}

The role of the mass transit system is to secure a city's transportation requirements at the required qualitative level. The quality of the mass transit system plays a significant role primarily in relation to the utilization of private automobile transport. Currently, private automobile transport in urban areas is problematic in its spatial requirements, increasing the number of traffic accidents and decreasing traffic flow speed, which is also reflected in the travel speed of mass transit transportation.

The only solution that can help encourage decreased use of private automobiles in urban areas is a high level of quality of passenger transportation. Although passenger transportation can be secured essentially without major issue from a quantitative aspect, user demands increase primarily in terms of quality. This is why the quality requirement for mass transit carrier services remains one of the goals of transportation policies in the Czech Republic (Ministry of Transport CR 2014). 
The issues involved in the assessment and measurement of the quality of services in the Czech Republic have begun to be reflected in many areas, and transportation is no exception. For quite some time, the concept of quality applied only to tangible products; usage in the service sectors is a relatively new notion (Hayes 1998; Hill, Roche, and Allen 2003; Nenadál et al. 2004). (This applies not only to the countries of Central and Eastern Europe, but to all other member countries of the European Community as well.) Issues related to quality began to be applied in transportation later than in other service sectors (European Standard EN 13816 2002; European Standard EN 15140 2006)). The reason is that quality (which has always been customer-centric) was not at the forefront of interest during the era of monopolized state carriers.

The United States was the first to take advantage of the practical applications of the theory of service quality in public transportation. According to TCRP Report 47 (Transportation Research Board 1999), which was led by a firm specializing in customer satisfaction measurement, the service sector in the U.S. began rigorously measuring quality in the 1980s, and the U.S. transit industry began adopting these practices in the 1990s. In addition, the research behind the first two editions of the Transit Capacity and Quality of Service Manual (Transportation Research Board 1999) spent considerable effort on identifying and quantifying, in a consistent way, quality factors that are important to passengers. Unfortunately, these documents were not available in the Czech Republic at the time.

Until 1998, there were no verified methods created for measuring customer satisfaction, nor have there been any studies that have dealt with the status and nature of public transport and its customers. This was due primarily to the lack of attention to this issue on a theoretical level. Methods and procedures with which one could comprehensively characterize and assess quality from the passenger point of view have not yet been established.

For the reasons listed, a method for evaluating transportation quality and transportation alternatives from the viewpoint of the passenger was created for this study (Olivková 2009). The study also included a questionnaire for a poll survey of transportation passengers. Experimental verification of both the method and questionnaire was carried out by conducting a comprehensive quality assessment of transportation and transportation alternatives in the Ostrava mass transit system based on the creation of a transportation survey of a selected group of travellers (Olivková 2009). Supplementing the quality assessment method with a measurement of passenger satisfaction emerged from the necessity to be able to objectively describe, compare, and interpret facts collected in a transportation survey.

The model was applied in practice in an actual case study of the mass transit system in Ostrava; the findings are presented in this paper. The goal is the assessment of both the theoretical and practical experiences related to the measurement of passenger satisfaction and assessment of mass transit quality. The model described herein and its scientific verification are the original work of the author. 


\section{Description of the Model}

To construct a model for measuring passenger satisfaction and assessing the quality of the mass transit system, the demands placed upon it must be defined:

- It must be a comprehensive model incorporating both a subjective component for measuring passenger satisfaction and an objective component for assessing the quality level of the mass transit system.

- It must include all relevant criteria (quantitative and qualitative) and must reflect the comprehensiveness of all aspects of the services.

- In addition to satisfaction, it must identify the importance of individual components of the services.

- It must guarantee expedient and financially feasible application, so that satisfaction assessment can be carried out regularly.

Taking into account all of the abovementioned demands, a model was devised and verified through implementation and is described in detail in the following sections.

\section{Defining Mass Transit Quality Criteria}

The criteria represent the views of the passengers on the services provided by mass transit. It is essential to pay close attention to the definitions of the mass transit quality criteria because this is an important step in the proposed methodology that can significantly influence the resulting overall assessment. The criteria set is designed to be exhaustive, i.e., it includes all of the significant mass transit quality components that are important to passengers. If this was not the case, it could lead to a skewing of the assessment results.

Six criteria were defined for the assessment of the quality assessment of the mass transit system, which fulfill and represent the concept of mass transit quality in the eyes of the passengers (Table 1). The criteria set contains two subsets: sub-criteria of the time and spatial offer of the mass transit systems, and vehicle comfort sub-criteria. 
TABLE 1.

Defining Mass Transit Quality Criteria

\begin{tabular}{|c|c|c|c|c|}
\hline No. & Criterion & $\begin{array}{l}\text { Sub- } \\
\text { Criterion } \\
\text { No. }\end{array}$ & Sub-Criterion & $\begin{array}{c}\text { Unit } \\
\text { of } \\
\text { Assessment }\end{array}$ \\
\hline 1 & Transit time & & & time (min) \\
\hline 2 & Punctuality & & & point scale \\
\hline \multirow{6}{*}{3} & \multirow{6}{*}{$\begin{array}{l}\text { Time and spatial offer of } \\
\text { mass transit system }\end{array}$} & 3.1 & Accessibility of stops & time (min) \\
\hline & & 3.2 & Waiting for connection & time (min) \\
\hline & & 3.3 & Transferability in mass transit network & time (min) \\
\hline & & 3.4 & Arrangement of stops & point scale \\
\hline & & 3.5 & Operational information & point scale \\
\hline & & 3.6 & Arrangement of ticket presales & point scale \\
\hline \multirow{5}{*}{4} & \multirow{5}{*}{ Comfort of vehicle } & 4.1 & Vehicle occupancy & point scale \\
\hline & & 4.2 & Noise level and vibrations & point scale \\
\hline & & 4.3 & Microclimate in vehicles & point scale \\
\hline & & 4.4 & Driving style & point scale \\
\hline & & 4.5 & Layout of interior of vehicles & point scale \\
\hline 5 & Transportation costs & & & point scale \\
\hline 6 & $\begin{array}{l}\text { Impact of mass transit system } \\
\text { on city's environment }\end{array}$ & & & point scale \\
\hline
\end{tabular}

All criteria listed in Table 1 have the same bearing from the passenger viewpoint. A lower nominal value of the given criteria is preferred (more useful) in the eyes of the passenger than a higher nominal value, and vice versa. The mass transit quality criteria can be divided into two groups according to manner of assessment (Carlsson and Fuller 1996):

a) Quantitative criteria - Nominal values were set objectively based on data on the individual components of transit time listed by passengers in the questionnaire.

b) Qualitative criteria - Nominal values were set subjectively by a passenger opinion survey on a five-point scale, where 1 is the best score (most desirable) and 5 is the worst score (least desirable).

\section{Establishing Mass Transit Quality Criteria Weight}

The assessment method must first establish the weight of the individual evaluation criteria that express the numeric meaning of the criteria (and/or the significance of the criteria from the evaluator's standpoint) (Fotr and Píšek 1986).

The following relationship is applied for establishing the non-normalised weight (Fiala, Jablonský, and Maňas 1994):

$$
\mathrm{k}_{\mathrm{i}}=\mathrm{n}+1-\mathrm{p}_{\mathrm{i}}
$$

where,

$$
\begin{aligned}
& k_{i}=\text { non-normalized weight of } i \text {-value criteria }[-] \\
& n=\text { quantity of criteria } \\
& \mathrm{p}_{\mathrm{i}}=\text { ranking of } \mathrm{i} \text {-value criteria in its preferential order }
\end{aligned}
$$


Due to the requirements of the comparability of criteria weights established by various methods, it is necessary to normalize these weights (the sum of the normalized weights of the set is equal to 1). Criteria weight normalization is carried out according to the following relationship (Fiala, Jablonský, and Maňas 1994):

$$
\mathrm{V}_{\mathrm{i}}=\frac{\mathrm{k}_{\mathrm{i}}}{\sum_{\mathrm{i}=1}^{\mathrm{n}} \mathrm{k}_{\mathrm{i}}}
$$

where,

$$
\begin{aligned}
& v_{i}=\text { normalized weight of } i \text {-value criteria }[-] \\
& k_{i}=\text { non-normalized weight of } i \text {-value criteria }[-] \\
& n=\text { quantity of criteria }
\end{aligned}
$$

For evaluating the quality level of the mass transit system, it was necessary to use an expanded set of criteria, which, for practical reasons, was divided into sub-groups according to the relationship of their substantive content (mass transit quality criteria, sub-criteria of the time and spatial offer of the mass transit systems, and sub-criteria of the comfort of the vehicle), and the following process of calculating criteria weight was applied:

- Respondents must prioritize the order of criteria based on their own subjective opinion. Based on this criteria ranking, the non-normalized weight of individual criteria is calculated and is then normalized so that the sum of the weights is equal to 1.

- The respondents then prioritize the order for each sub-criterion whose classification and significance create a subset of the specific criteria. Based on this sub-criteria ranking, the non-normalized weight of the individual sub-criteria is calculated; these are then also normalized.

- The resulting sub-criteria weights are always calculated by multiplying the subcriteria weights by the weight of the criteria under which it is categorized.

Normalization of criteria weight as well as the weights of the individual sub-criteria then ensure that the resulting sub-criteria weights calculated by the abovementioned multiplication process are once again normalized, so that their sum across the entire criteria set equals 1 .

The advantage of this process of establishing weights is based primarily in the fact that it decreases the demand on the user (passenger), who only needs to determine the preferential order of the criteria and immediately relevant sub-criteria. They are, therefore, not required to judge the significance (importance) of other, entirely substantively different criteria.

One final important aspect regarding establishing criteria weight is that the reliability of obtained results can be increased by utilizing a greater number of respondents (passengers) who determine criteria order individually and independently of one another. 


\section{Mass Transit Criteria Assessment}

In the assessment of mass transit quality criteria, it may happen that a portion of the criteria is quantitative in nature (values are expressed on a metrical scale) and a portion is qualitative in nature (values are expressed on an ordinal scale). The means to achieve a statistical assessment typical for metrical scales while using ordinal rankings is through metrization, i.e., assigning point values on a point scale (Moreno, Fidélis, and Ramos 2014). For each position on the point scale, the level for each quality criteria is precisely defined using word descriptors. By assigning points from a point scale, the passenger determines to which degree the given criterion fulfills his/her expectations. Qualitative criteria nominal values are thus expressed subjectively based on the viewpoint of the passenger in scale values. Subjectively-expressed viewpoints can then be statistically objectivized.

Assessment of mass transit quality quantitative criteria (sub-criteria) is divided into the following steps:

1. Construction of criteria sub-utility functions.

a) Definition the domain of the sub-utility functions - The domain of the criteria sub-utility function is the interval of nominal values $x_{i}=\left\langle x_{i \min } ; x_{i \max }\right\rangle$. Nominal values are established objectively, based on quantitative data (on a metric scale) provided by passengers in the questionnaire. The endpoints of this interval can be labeled as $x_{i \min }$ and $x_{i \max }$, where $x_{i \min }$ is the lowest (minimum) value of $i$-value criteria and $x_{i \max }$ is the highest (maximum) value of i-value criteria.

b) Graphical representation of the investigation of the surveyed values using a dot chart - Through the use of a five-point scale of quality criteria assessment, where 1 represents the best score and 5 the worst, passengers assign the specific criteria nominal value $x_{i}$ a utility value $u_{i}=1, u_{i}=0.75, u_{i}=0.5, u_{i}=$ 0.25 or $u_{i}=0$. Ordered pairs $\left(x_{i}, u_{i}\left(x_{i}\right)\right)$ create point coordinates that can be illustrated graphically using a dot chart in which criteria nominal values are plotted on the $x$-axis and the corresponding mean utility values are plotted on the $y$-axis.

c) Determination of the type of regression function (criteria sub-utility function) and establishing its parameters using the method of least squares - The method of least squares can help identify the regression (approximation) function with the smallest sum of squared deviations of the observed (surveyed) values from the calculated (theoretical) $y_{i} /$. The method of least squares consists of finding a regression (approximation) function for which the following relationship applies (Meloun and Militký 2002):

$$
\sum_{i=1}^{n}\left(y_{i}-y_{i}^{\prime}\right)^{2}=\min
$$


The procedure is as follows:

From the dot chart depicting values identified by the survey, it can be concluded that the dependence is quadratic. The function $u_{i}\left(x_{i}\right)$ will be monotonically decreasing in its domain $x_{i}=\left\langle x_{\text {imin }} ; x_{\text {imax }}\right\rangle$. Two types of $u_{i}\left(x_{i}\right)$ functions can be expected, i.e., convex (Figure 1, type a) or concave utility functions (Figure 1, type c).

FIGURE 1.

Types of criteria subutility function $\mathrm{u}_{\mathrm{i}}\left(\mathrm{X}_{\mathrm{i}}\right)$

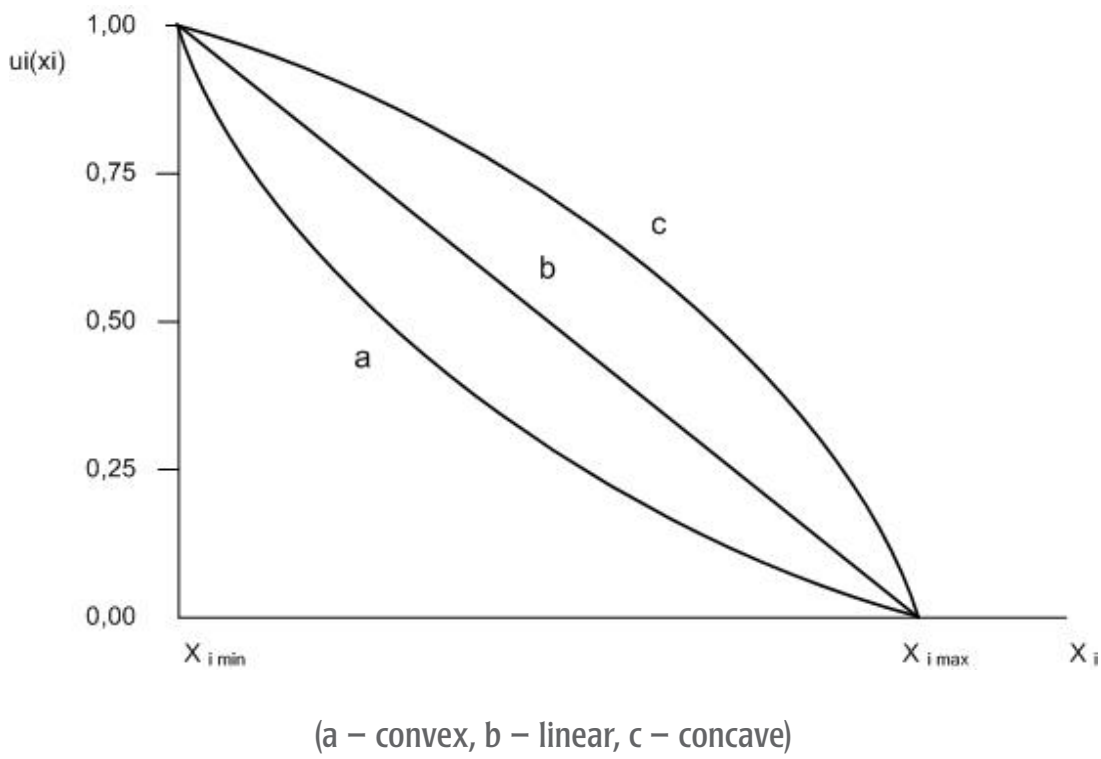

Surveyed values can, therefore, be approximated parabollically (quadratic function, second-order polynomial) with the equation $y=f(x)=a x^{2}+b x+$ c. Estimations of their parameters can be obtained using the method of least squares, i.e., from conditions so that the sum of the squared deviations $S$ were minimal (Anděl 2007):

$$
S(a, b, c)=\sum_{i=1}^{n}\left(y_{i}-a x_{i}^{2}-b x_{i}-c\right)^{2}=\min
$$

The coefficient of determination indicates in what part the variability of the dependent value is explained by the chosen model (Meloun and Militký 2002):

$$
I^{2}=\frac{\sum_{i=1}^{n}\left(y_{i}^{\prime}-\bar{y}\right)^{2}}{\sum_{i=1}^{n}\left(y_{i}-\bar{y}\right)^{2}}
$$

The coefficient of determination (labeled as $\mathrm{R}^{2}$ in Microsoft Excel) takes on the values of the closed interval $\langle 0,1\rangle$. 
2. Division of the domain of the criteria sub-utility functions into nominal value intervals and setting nominal value limits.

The domain function can be divided into five nominal value sub-intervals by transforming the quality criteria point value using the sub-utility function of $u_{i}\left(x_{i}\right)$ criteria. Using the $u_{i}\left(x_{i}\right)$ function, we can also get the limit of the nominal values $x_{i}^{1}, x_{i}^{0.75}, x_{i}^{0.5}, x_{i}^{0.25}, x_{i}{ }^{0}$ for which $u_{i}\left(x_{i}\right)$ takes on the values $u_{i}\left(x_{i}{ }^{1}\right)=1, u_{i}\left(x_{i}{ }^{0.75}\right)=0.75$, $u_{i}\left(x_{i}^{0.5}\right)=0.5, u_{i}\left(x_{i}^{0.25}\right)=0.25$ and $u_{i}\left(x_{i}^{0}\right)=0$. Assessment of mass transit quality qualitative criteria (sub-criteria) is divided into the following steps:

a) Construction of criteria sub-utility functions.

i) Definition the domain of the sub-utility functions - The domain of the sub-utility function is the nominal value limits of criteria $x_{i}=1, x_{i}=2, x_{i}=3$, $x_{i}=4, x_{i}=5$ that were established subjectively based on qualitative data, provided by passengers in the survey.

ii) Graphical representation of the surveyed values using a dot chart Through the use of a five-point scale of quality criteria assessment, where 1 represents the best score and 5 the worst, passengers assign the nominal value limits $x_{i}=1, x_{i}=2, x_{i}=3, x_{i}=4, x_{i}=5$, for which $u_{i}\left(x_{i}\right)$ take on values $u_{i}(1)=1, u_{i}(2)=0.75, u_{i}(3)=0.5, u_{i}(4)=0.25$ and $u_{i}(5)=0$. Ordered pairs $\left(x_{i}\right.$ $\left.u_{i}\left(x_{i}\right)\right)$ create five point coordinates that can be graphically depicted using a dot chart with the $x$-axis plots the limits of the criteria nominal values, and the $y$-axis reflect the corresponding utility values.

iii) Determination of the type of regression function (criteria sub-utility function) and establishing its parameters using the method of least squares - From the dot chart depicting criteria values identified by the survey, it can be concluded that the dependence is linear. The function $u_{i}\left(x_{i}\right)$ will be linearly monotonically decreasing in its domain $x_{i}=\left\langle x_{i m i n}\right.$; $x_{\text {imax }}>$ (Figure 1, type b). Values provided by the survey can, therefore, be approximated by a straight line (first-order polynomial) with the equation $y=f(x)=a x+b$. Estimations of their parameters can be obtained using the method of least squares, i.e., from conditions so that the sum of the squared deviations $S$ are the smallest possible (Andèl 2007):

$$
S(a, b)=\sum_{i=1}^{n}\left(y_{i}-a x_{i}-b\right)^{2}=\min
$$

The appropriateness of the regression function can again be verified through the coefficient of determination (5).

b) Division of the domain of the criteria sub-utility function into nominal value intervals and setting nominal value limits - This step cannot be carried out for qualitative criteria because the sub-utility domain cannot be divided into nominal value intervals. The domain is created solely by nominal value limits. 


\section{Model Application Results}

From 2011 to 2014, the model for measuring satisfaction and assessment of quality described above was implemented in Ostrava. A total of 2,120 respondents were surveyed, with 540 respondents being surveyed in 2011, 521 in 2012, 543 in 2013, and 516 in 2014.

The transportation survey focused on the residents of Ostrava and the surrounding area that utilize the mass transit system as a means of transportation on their way to work (or school). It did not include residents of other cities or users of the integrated transport system who use other systems of mass passenger transportation (bus and railway passenger transportation) and transfer to the urban mass transit system to travel from their place of residence to their place of work. One of the reasons was to focus the survey on passenger satisfaction assessment of the urban mass transit system. Another reason was the possibility of decreased objectivity in assessing the quality criteria of the urban mass transit system resulting from the use of a different transportation system during the course of travel. All types of mass transit system modes of transportation used by Ostrava Transport (buses, trams, trolley bus) or the combination thereof, in the case of transfers, are represented.

Taking into account similar surveys and personal experience from a study conducted in 2009 (Olivková 2009), the selection of surveyed individuals was carried out in the individual city districts of Ostrava based on a proportional representation according to the socio-demographic quota characteristics of the city. Interviewers were assigned a specific area in which they were to conduct their surveys as well as a quota according to sex, age, and level of completed education. Based on the results and measurements of already-completed studies in which quota sampling was used, the generallyrecommended sample size was 500 or more statistical units (Nenadál et al. 2004).

The surveys were conducted in the form of face-to-face interviews. Respondents filled out a questionnaire in the presence of a trained individual (students of the Institute of Transportation, VŠB-Technical University of Ostrava) who oversaw the completion of the questionnaire. This also ensured that passengers could ask for clarification if they did not understand any of the presented questions.

\section{Evaluation of Respondent Data}

The following results apply to a defined base set-mass transit users over the age of 15 and who, in principle, can make their own decisions on the choice of mode of transportation. Evaluation of respondent data is depicted in Table 2, which presents both absolute and relative frequencies, expressed in percentages, for the individual years 2011-2014 and overall. 
TABLE 2.

Evaluation of Respondent

Data

\begin{tabular}{|c|c|c|c|c|c|c|c|c|c|c|c|}
\hline \multirow{2}{*}{$\begin{array}{c}\text { Respondent } \\
\text { Data }\end{array}$} & \multirow[t]{2}{*}{ Class } & \multicolumn{5}{|c|}{$\begin{array}{c}\text { Absolute Frequency } \\
\text { (person) }\end{array}$} & \multicolumn{5}{|c|}{$\begin{array}{l}\text { Relative Frequency } \\
\text { (\%) }\end{array}$} \\
\hline & & 2011 & 2012 & 2013 & 2014 & Sum & 2011 & 2012 & 2013 & 2014 & Avg. \\
\hline \multirow{2}{*}{ Sex } & Man & 226 & 234 & 216 & 214 & 890 & 42 & 45 & 40 & 41 & 42 \\
\hline & Woman & 314 & 287 & 327 & 302 & 1230 & 58 & 55 & 60 & 59 & 58 \\
\hline \multirow{4}{*}{ Age } & Up to 26 & 130 & 115 & 152 & 139 & 530 & 24 & 22 & 28 & 27 & 25 \\
\hline & $26-44$ & 221 & 224 & 185 & 175 & 806 & 41 & 43 & 34 & 34 & 38 \\
\hline & $45-59$ & 157 & 135 & 152 & 165 & 615 & 29 & 26 & 28 & 32 & 29 \\
\hline & 60 & 32 & 47 & 54 & 36 & 170 & 6 & 9 & 10 & 7 & 8 \\
\hline \multirow{3}{*}{$\begin{array}{l}\text { Level of } \\
\text { education }\end{array}$} & Elementary & 113 & 78 & 60 & 72 & 318 & 21 & 15 & 11 & 14 & 15 \\
\hline & Secondary & 346 & 401 & 413 & 387 & 1548 & 64 & 77 & 76 & 75 & 73 \\
\hline & Higher & 81 & 42 & 71 & 57 & 254 & 15 & 8 & 13 & 11 & 12 \\
\hline \multirow{4}{*}{$\begin{array}{l}\text { Frequency } \\
\text { of use of } \\
\text { mass transit } \\
\text { system }\end{array}$} & Daily & 378 & 328 & 353 & 356 & 1420 & 70 & 63 & 65 & 69 & 67 \\
\hline & $\begin{array}{l}\text { 3-4 times } \\
\text { per week }\end{array}$ & 86 & 104 & 114 & 77 & 382 & 16 & 20 & 21 & 15 & 18 \\
\hline & $\begin{array}{l}1-2 \text { times } \\
\text { per week }\end{array}$ & 54 & 47 & 43 & 67 & 212 & 10 & 9 & 8 & 13 & 10 \\
\hline & Less & 22 & 42 & 33 & 15 & 106 & 4 & 8 & 6 & 3 & 5 \\
\hline
\end{tabular}

\section{Evaluation of Criteria in Terms of Subjective Importance}

The process described previously was used to calculate the weights of individual criteria (sub-criteria). From the collected data, average percentage representations of weight (level of relative importance) can be determined for:

- Mass transit quality criteria (Figure 2)

- Time and spatial offer of the mass transit systems sub-criteria (Figure 3)

- Vehicle comfort sub-criteria (Figure 4)

FIGURE 2.

Average percentage representations of weight

for mass transit quality criteria

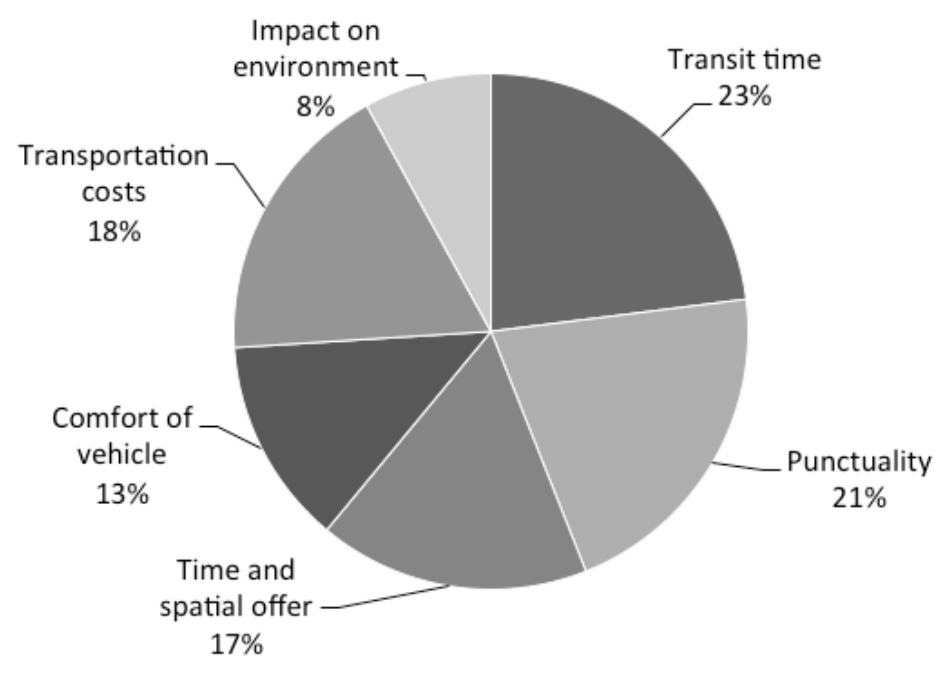


FIGURE 3.

Average percentage representations of weight for time and spatial offer of mass transit systems sub-criteria

FIGURE 4.

Average percentage representations of weight

for vehicle comfort sub-criteria
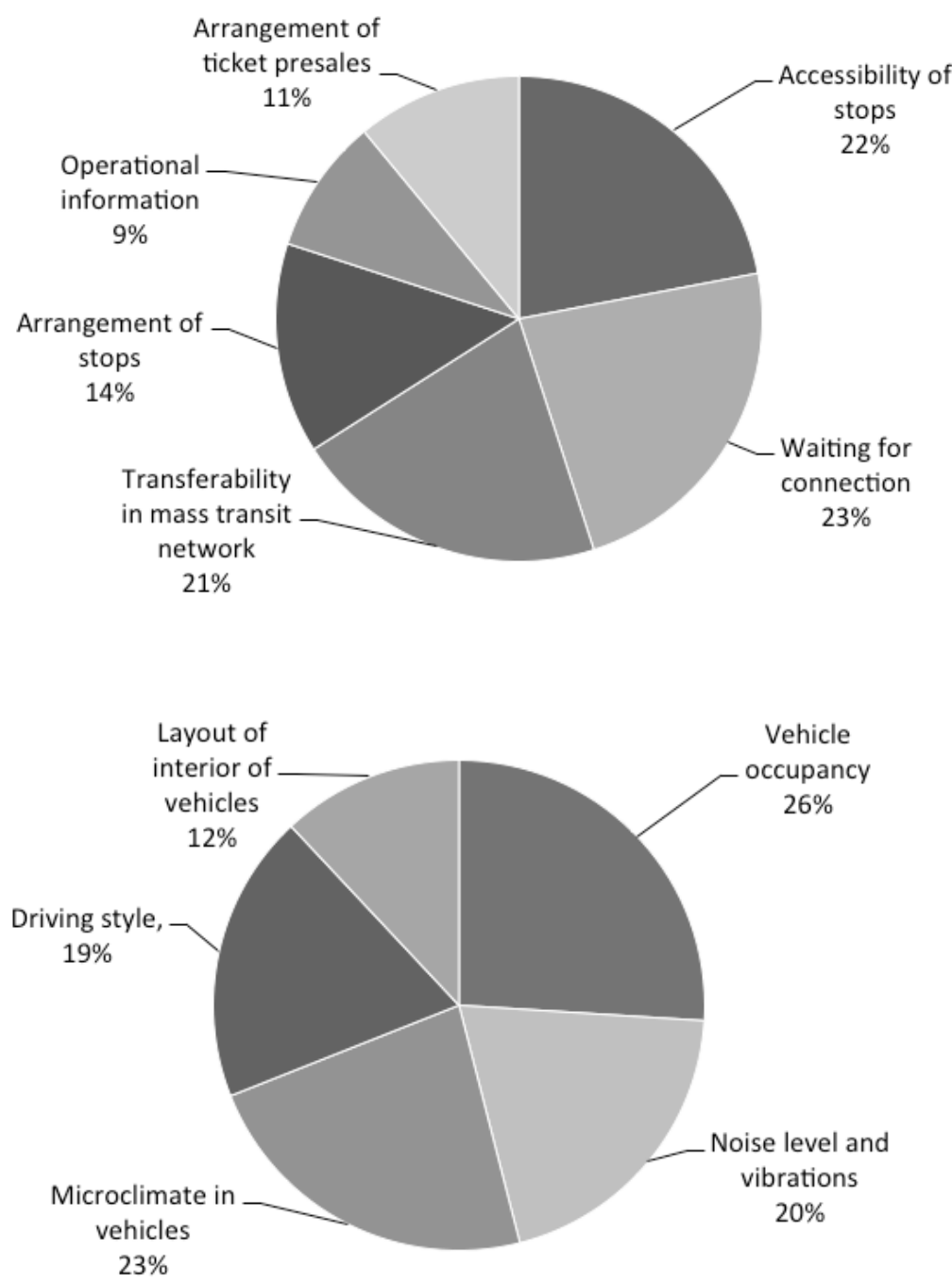

Figure 2 indicates the following weight ranking of mass transit quality criteria from the point of view of the passengers:

- Transit time (total travel time) - Passengers prefer that the time spent traveling to work be as short as possible.

- Punctuality, (adherence to prescribed timetable) - Passengers require the greatest accuracy possible in adherence to the mass transit system timetable.

- Transportation costs - Passengers expect low fare costs.

- Time and spatial offer of mass transit systems - Passengers require the greatest level of comfort possible outside of transportation vehicles. As is shown in Figure 3 , this requirement applies primarily to short connection waiting times and accessibility of stops, which is related to the abovementioned requirement for short travel times.

- Comfort of the vehicle - Passengers expect acceptable levels of comfort inside the vehicle. Figure 4 indicates that this requirement applies primarily to low 
occupancy (sufficient space for seated and standing passengers) and microclimate (sufficient ventilation, heating, and lighting, i.e., securing optimal temperature and lighting conditions).

- Impact of the mass transit system on the city's environment - From the viewpoint of the passengers, mass transit pollutes the city's environment with noise, vibrations, air pollution from emissions and exhaust, and fuel and oil leakage to a much lesser extent than private automobile transportation.

\section{Assessing Mass Transit Quality Criteria in Terms of Passenger Satisfaction}

The procedure for assessing quality criteria in terms of passenger satisfaction depends on the nature of the criteria. Assessment of quantitative criteria is governed by the procedures described previously and was determined by conducting an assessment of the transit time criteria.

Transit time is considered one of the most significant criteria that impacts a passenger's decision to utilize mass transit transportation options. If a passenger has the opportunity to choose from a selection of several types of means of transportation (including automobiles) to reach a specific travel destination, the "door-to-door" transit time (total travel time) is essential. Transit time, therefore, is defined as (Surovec 1998):

$$
t_{p}=t_{1}+t_{\check{c}}+t_{d p}+t_{p \check{r}}+t_{2}
$$

where,

$$
\begin{aligned}
& t_{p}=\text { transit time (min) } \\
& t_{1}=\text { time spent walking to initial stop (min) } \\
& t_{\check{c}}=\text { connection wait time (min) } \\
& t_{d p}=\text { time spent traveling in the mass transit vehicle, transport time (min) } \\
& t_{p \check{r}}=\text { connection transfer time (including time spent waiting at a connecting stop) } \\
& \quad \text { (min) } \\
& t_{2}=\text { time spent walking from final stop to place of employment (min) }
\end{aligned}
$$

The criterion of transit time was assessed by passengers in terms of time spent traveling from their residence to their place of employment. Nominal values of transit time $x_{1}$ were calculated based on the data of the individual components of transit time (7) obtained from passengers in the survey.

On a scale from 1 to 5 , passengers assigned the specific nominal value of $x_{1}$ a utility value $u_{1}=\langle 1 ; 0\rangle$. Ordered pairs $\left(x_{1} u_{1}\left(x_{1}\right)\right)$ create point coordinates that are illustrated graphically in Figure 5 (the $x$-axis plots the transit time nominal values, and the $y$-axis reflects the corresponding average utility values). Values collected by the survey can be best approximated by a parabola (quadratic function, second-order polynomial). 
FIGURE 5.

Sub-utility function of transit time

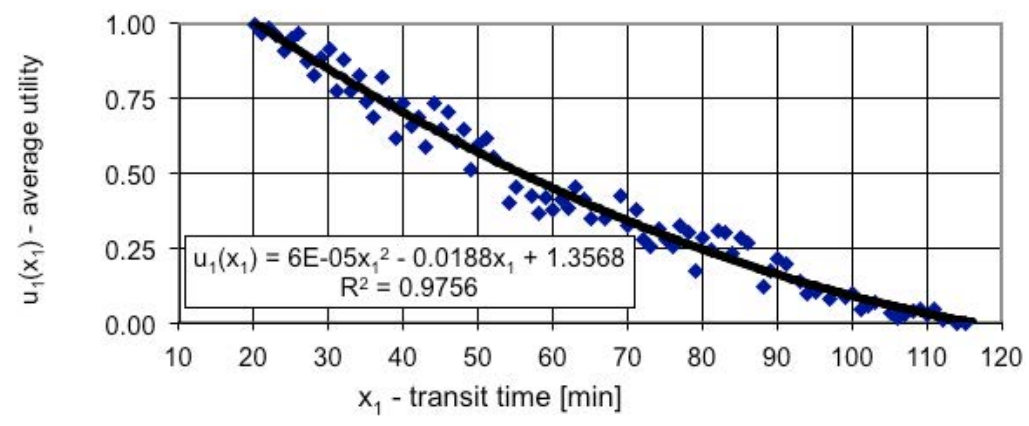

The sub-utility function $\mathrm{u}_{1}\left(\mathrm{x}_{1}\right)$ has the form:

$$
\mathrm{u}_{1}\left(\mathrm{x}_{1}\right)=6 \mathrm{E}-05 \mathrm{x}_{1}^{2}-0.0188 \mathrm{x}_{1}+1.3568
$$

The coefficient of determination $\mathrm{R}^{2}=0.9756$, which signifies good point spacing.

The function $u_{1}\left(x_{1}\right)$ in its domain $x_{1}=\langle 20 ; 115>$ is monotonically decreasing from the function value $u_{1}\left(x_{1}^{1}\right)=1$ to the function value $u_{1}\left(x_{1}{ }^{0}\right)=0$; the behavior of the function is convex. Additions to the nominal values at the beginning of the domain represent a greater decrease in utility for passengers than additions of nominal values at the end of the domain.

The domain function was divided based on point scores assigned by passengers into five separate intervals (Table 3). Using the function $u_{1}\left(x_{1}\right)$, one can also get limits of nominal values $x_{1}{ }^{1}, x_{1}{ }^{0.75}, x_{1}{ }^{0.5}, x_{1}{ }^{0.25}, x_{1}{ }^{0}$ for which $u_{1}\left(x_{1}\right)$ takes on the value $u_{1}\left(x_{1}{ }^{1}\right)=1, u_{1}\left(x_{1}{ }^{0.75}\right)=$ $0.75, u_{1}\left(x_{1}^{0.5}\right)=0.5, u_{1}\left(x_{1}^{0.25}\right)=0.25$, and $u_{1}\left(x_{1}{ }^{0}\right)=0$.

TABLE 3.

Division of Domain of Criteria Sub-Utility Functions

\begin{tabular}{|c|l|c|c|}
\hline \multicolumn{2}{|c|}{ Point Scores } & $\begin{array}{c}\text { Nominal Value } \\
\text { Intervals } \mathbf{x}_{\mathbf{1}}(\mathbf{m i n})\end{array}$ & $\begin{array}{c}\text { Nominal Value } \\
\text { Limits } \mathbf{x}_{\mathbf{1}}(\mathbf{m i n})\end{array}$ \\
\hline 1 & Very satisfied & $20-28$ & 20 \\
\hline 2 & Satisfied & $29-45$ & 37 \\
\hline 3 & Neither satisfied nor dissatisfied & $46-65$ & 55 \\
\hline 4 & Dissatisfied & $66-93$ & 79 \\
\hline 5 & Very dissatisfied & $94-115$ & 115 \\
\hline
\end{tabular}

The values listed in Table 3 indicate how passengers assess time spent in transit from their residence to their place of employment. Reaching the travel destination (place of employment) within 28 minutes brings the highest utility for passengers, although they indicated that they were "satisfied" with times of up to 45 minutes. Increasing time spent traveling to up to 65 minutes were labeled as neutral- "neither satisfied nor dissatisfied"; additional increases, however, were viewed by passengers as unacceptable.

The evaluation of qualitative criteria is governed by the procedures described in the previous sesction. Since the procedures for constructing sub-utility functions for the individual qualitative criteria is identical, it is described in general terms for all of these criteria. 
Through the use of a five-point quality criteria assessment scale, where 1 represents the best score and 5 the worst, passengers assigned the nominal value limits $x_{i}=<1$; $5>$ for which $u_{i}\left(x_{i}\right)$ takes on the values $u_{i}(1)=1, u_{i}(2)=0.75, u_{i}(3)=0.5, u_{i}(4)=0.25$ and $u_{i}(5)=0$. Ordered pairs $\left(x_{1}, u_{1}\left(x_{1}\right)\right)$ create five point coordinates that are plotted in Figure 6 (the $x$-axis plots the limits of the criteria nominal values, and the $y$-axis plots the corresponding average utility values). These points can be best represented by a linear regression curve. The sub-utility functions of qualitative criteria $u_{i}\left(x_{i}\right)$ have the form:

$$
\mathrm{u}_{\mathrm{i}}\left(\mathrm{x}_{\mathrm{i}}\right)=-0.25 \mathrm{x}_{\mathrm{i}}+1.25
$$

The coefficient of determination $\mathrm{R}^{2}=1$ which means that the curve passes through the specified points.

FIGURE 6.

Sub-utility functions of qualitative criteria $\mathrm{u}_{\mathrm{i}}\left(\mathrm{x}_{\mathrm{i}}\right)$

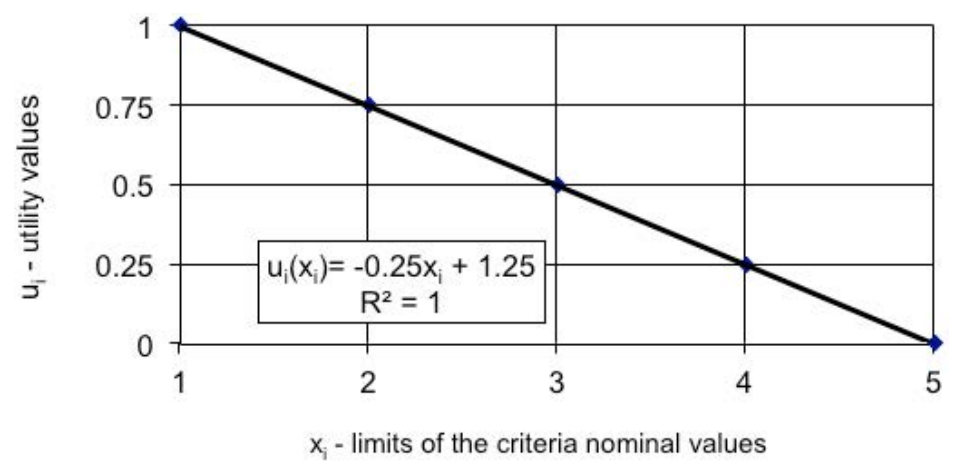

The sub-utility functions of qualitative criteria $u_{i}\left(x_{i}\right)$ in the domain $x_{i}=\langle 1 ; 5\rangle$ is monotonically deceasing from the function value $u_{i}\left(x_{i}^{1}\right)=1$ to the function value $u_{i}$ $\left(\mathrm{x}_{\mathrm{i}}{ }^{0}\right)=0$; the behavior of the function is linear. Qualitative criteria have a decreasing preference in which constant growth of the nominal value means a constant decrease in utility value for the respondents.

Table 4 lists the average values (utility) of individual criteria that were calculated overall for all passengers (respondents) who participated in the survey both for the individual years 2011-2014 and overall. 
TABLE 4.

Average Values (Utility) of Individual Criteria

\begin{tabular}{|c|c|c|c|c|c|c|}
\hline \multirow{2}{*}{$\begin{array}{c}\text { Criterion } \\
\text { No. }\end{array}$} & \multirow{2}{*}{ Criteria } & \multicolumn{4}{|c|}{$\begin{array}{c}\text { Average Values (Utility) of } \\
\text { Criteria }\end{array}$} & \multirow{2}{*}{$\begin{array}{c}\text { Average } \\
\text { 2011-2014 }\end{array}$} \\
\hline & & 2011 & 2012 & 2013 & 2014 & \\
\hline 1 & Transit time & 0.51 & 0.52 & 0.55 & 0.58 & 0.54 \\
\hline 2 & Punctuality & 0.67 & 0.76 & 0.73 & 0.77 & 0.73 \\
\hline 3.1 & Accessibility of stops & 0.86 & 0.83 & 0.8 & 0.82 & 0.83 \\
\hline 3.2 & Waiting for connection & 0.76 & 0.72 & 0.7 & 0.74 & 0.73 \\
\hline 3.3 & Transferability in transit network & 0.46 & 0.42 & 0.48 & 0.41 & 0.44 \\
\hline 3.4 & Arrangement of stops & 0.60 & 0.58 & 0.66 & 0.68 & 0.63 \\
\hline 3.5 & Operational information & 0.63 & 0.64 & 0.67 & 0.68 & 0.66 \\
\hline 3.6 & Arrangement of ticket presales & 0.54 & 0.48 & 0.51 & 0.56 & 0.52 \\
\hline 4.1 & Vehicle occupancy & 0.41 & 0.48 & 0.49 & 0.45 & 0.46 \\
\hline 4.2 & Noise level and vibrations & 0.68 & 0.65 & 0.67 & 0.70 & 0.68 \\
\hline 4.3 & Microclimate in vehicles & 0.69 & 0.67 & 0.65 & 0.66 & 0.67 \\
\hline 4.4 & Driving style & 0.48 & 0.45 & 0.46 & 0.5 & 0.47 \\
\hline 4.5 & Layout of interior of vehicles & 0.74 & 0.78 & 0.76 & 0.79 & 0.77 \\
\hline 5 & Transportation costs & 0.52 & 0.46 & 0.48 & 0.42 & 0.47 \\
\hline 6 & Impact of the city's environment & 0.49 & 0.44 & 0.47 & 0.46 & 0.47 \\
\hline
\end{tabular}

It can be stated that eight criteria scored, on average, above 0.604 (the average level of satisfaction), i.e., passengers were satisfied with them. Seven criteria scored below this threshold, i.e., respondents were dissatisfied with them, which indicates a potential for improvement for the carrier. The following section discusses which quality criteria are in need of immediate improvement.

\section{Evaluating the Results of the Satisfaction Survey}

Evaluation of the results of the study was conducted using Strengths-WeaknessesOpportunities-Threats (SWOT) analysis (Figure 7). It comprises a two-dimensional graph that graphically depicts the relationship of passenger satisfaction with the given criteria (vertical axis) and its true significance (horizontal axis). To interpret and evaluate the significance of individual criteria for further decision-making on the part of the carrier, each SWOT table was divided by a horizontal and vertical line into four quadrants. The horizontal dividing line creates the average level of satisfaction, and the vertical is the position level of the true significance of all criteria-the median of subjectively-perceived importance. 


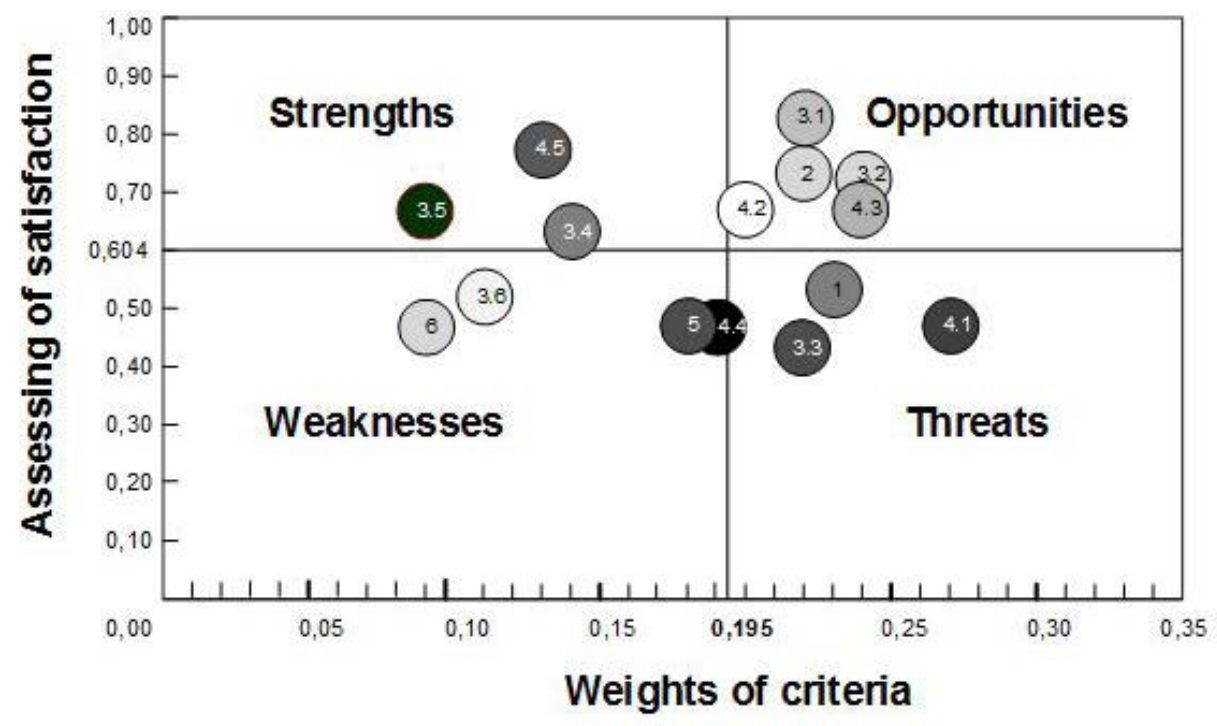

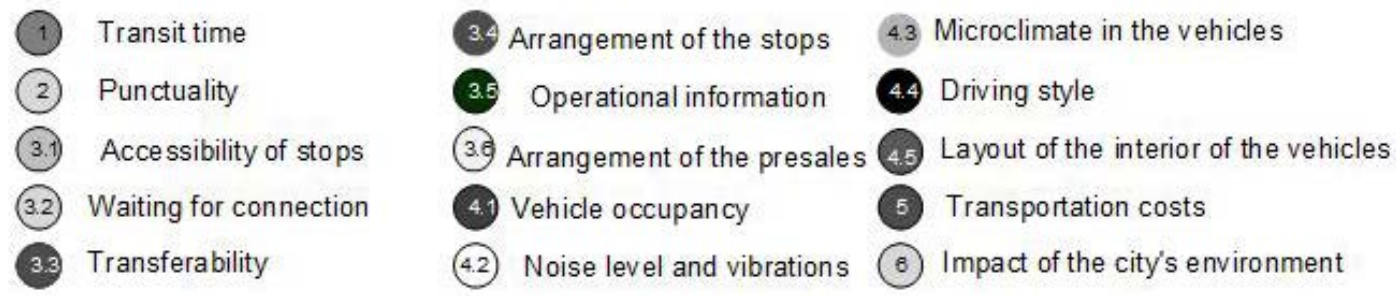

FIGURE 7. Results of satisfaction survey for 2011-2014 overall (SWOT)

Overall, the services of the DP Ostrava transportation company earned a very high rating (Figure 7). This is evidenced by the position of the elements in the SWOT table in which, of the 15 evaluated quality elements, only 3 are listed under "Threats." These criteria have a large impact on overall passenger satisfaction but have a negative rating. Therefore, they represent a significant threat to the company, and it is imminently necessary to implement corrective measures. Among these criteria is transit time, transferability in the mass transit network, and vehicle occupancy.

Special attention must be paid to the criterion of travel time. This quality component is significant for the overall assessment of mass transit services in Ostrava. Its average rating is unsatisfactory-passengers are not satisfied with the time it takes to travel from their point of departure to their destination. Put simply, passengers feel that the mass transit system is not fast enough. It is interesting that there are no significant differences of opinion in this area between the individual socio-demographic groups of transportation clients.

Since transfer time is also a critical component of mass transit quality in Ostrava with a significant impact on the satisfaction evaluation by passengers and is a significant part of travel time, it is important to take action in this particular area. Reducing the number of transfers, and thus decreasing transfer time, can significantly shorten the total travel time. 
There are five criteria in the "Opportunities" section, which have a heavy impact on overall passenger satisfaction, and, additionally, have a positive rating. The carrier can be satisfied with its assessment. The important thing is to maintain a high level of quality in following years as well. These criteria include punctuality, accessibility of stops, connection wait times, noise level and vibrations, and microclimate in the vehicles.

There are three criteria in the "Strengths" section, which have a relatively small impact on overall passenger satisfaction, but have a positive rating. These criteria include the layout of the interior of the vehicles, operational information, and arrangement of the stops.

In the "Weaknesses" section are four criteria: arrangement of the ticket presales, transportation costs, driving style, and impact of mass transit on the city's environment, which, although they have a below-average rating, are not as important to passengers. It is important to take note of the sub-criteria, driving style, which could be reclassified under the "Threats" label with even a slight increase in their weight value.

\section{Conclusions}

This paper studies the issues of measuring passenger satisfaction and assessing mass transit quality. It focuses specifically on a description of the model and the results of its experimental verification, carrying out a passenger satisfaction assessment and assessing the quality of the Ostrava mass transit system. The model was scientifically verified by conducting a transportation survey of passengers (Ostrava mass transit system users) that took place in 2011-2014. Quality criteria were rated by passengers in the questionnaire. Respondents were approached at their place of employment by a trained individual who supervised the proper completion of the questionnaire in its entirety.

The experimental verification indicated the following:

- The advantage of the model described in the paper lies in its theoretical reasoning.

- Since there is currently no existing established and commonly-used comprehensive method that includes both a passenger satisfaction assessment and a quality assessment of the mass transit system, the model described is an asset to the development of transportation science.

- Passenger satisfaction and mass transit quality can be comprehensively assessed by implementing the model, using mixed set criteria containing both qualitative and quantitative criteria, in which their informative value is not limited.

- Results indicating the model's suitability for practical application in assessing the satisfaction with and quality of the mass transit system in the eyes of passengers are significant to evaluating the model itself, because they allow for:

- identification of passenger expectations related to the level of quality of the mass transit system

- identification of the existing level of quality

- revealing the causes of passenger dissatisfaction 
- revealing the strengths and weaknesses of the carrier

- providing information and data for quality improvement projects

- quantified results with the opportunity for trend assessment

The model's primary advantages include the opportunity to present the basic results of the survey. By combining the values of satisfaction and importance for individual criteria or groups thereof can help formulate conclusions on the necessity of further action by the carrier.

A number of relevant methods of measuring the performance and satisfaction are described in the European Standard of Service (European Standard EN 13816 2002), and several examples of their utilization in public passenger transportation are listed. This norm is established as a source for defining service quality areas, both for objective measurement and also more recently for subjective CSS measurements (for example, Trompet et al. 2013). The method proposed by the standard for measuring customer satisfaction allows for more of a component (isolated) assessment of the individual quality criteria of urban mass transit travel; it does not address a comprehensive assessment of the quality of mass transit travel from the standpoint of all of the criteria. The standard allows for the use of alternative methods under the assumption that they will provide equivalent results. This is why using the model presented in this paper is recommended as an alternative to the methods suggested by the European Standard of Service.

\section{References}

Anděl, Jiří. 2007. Statistické Metody. Matfyzpress Praha.

Carlsson, Christer, and Robert Fullér. 1996. "Fuzzy Multiple Criteria Decision Making: Recent Developments." Fuzzy Sets and Systems, 78 (2): 139-153.

European Standard EN 13816. 2002. "Transportation—Logistics and Services-Public Passenger Transport-Service Quality Definition, Targeting and Measurement." Brussels. European Committee of Standardization.

European Standard EN 15140. 2006. "Public Passenger Transport-Basic Requirements and Recommendations for Systems that Measure Delivered Service Quality." Brussels. European Committee for Standardization.

Fiala, Petr, Josef Jablonský, and Miroslav Maňas. 1994. "Vícekriteriální Rozhodování."

Fotr, Jiří, and Milan Píšek. 1986. "Exaktní Metody Ekonomického Rozhodování." ACADEMIA Praha, 1986.

Hayes, Bob E. 1998. Measuring Customer Satisfaction. Milwaukee: ASQ Quality Press.

Hill, Nigel, Greg Roche, and Rachel Allen. 2003. Customer Satisfaction: The Customer Experience Through The Customer's Eyes. Cogent Publishing.

Meloun, Milan, and Jiří Militký. 2002. "Kompendium Statistického Zpracování Dat." Praha. 
Ministry of Transport CR. The Transport Policy of Czech Republic for 2014-2020 with Perspective to 2050. Available at http://www.mdcr.cz/NR/rdonlyres/DB292074-62B44B09-9D43-9697A1A86FB0/0/B1300298_MINISTERSTVO_DOPRAVY_2014_2020_ ENG05.pdf.

Moreno, Pires S., Teresa Fidélis and Tomás Ramos. 2014. "Measuring and Comparing Local Sustainable Development through Common Indicators: Constraints and Achievements in Practice." Cities, 39: 1-9.

Nenadál, Jan, et al. 2004. "Modely Měření a Zlepšování Spokojenosti Zákazníků. Národní Informační Středisko Pro Podporu Jakosti." Praha.

Olivková, Ivana. 2009. Urban Mass Transportation Quality Evaluation from Passenger's Points of View. Sborník Vědeckých Prací FS. VŠB-TU Ostrava: 211-216.

Olivková, Ivana. 2009. "Urban Mass Transportation Quality Evaluation and the Concept of Quality Standards." Inaugural dissertation, VŠB-Technical University of Ostrava.

Surovec, Pavel. 1998. Technológia Hromadnej Osobnej Dopravy (Cestná a Mestská Doprava). Žilinská Univerzita, EDIS Žilina.

Transportation Research Board. 1999. TCRP Report 47, A Handbook for Measuring Customer Satisfaction and Service Quality. National Academy Press, Washington, DC.

Transportation Research Board. 1999. TCRP Report 100, Transit Capacity and Quality of Service Manual. National Academy Press, Washington, DC.

Trompet, Mark, Richard Parasram, and Richard J. Anderson. 2013. "Benchmarking Disaggregate Customer Satisfaction Scores between Bus Operators in Different Cities and Countries." Transportation Research Record, 2351: 14-22.

\section{About the Author}

IVANA OlivkovÁ, Ph.D. (ivana.olikova@vsb.cz), works as an Associate Professor in the Institute of Transport at the VŠB-Technical University of Ostrava. Her areas of interest include public transport, evaluation the quality of public transport, application of decision support methods, intelligent transport systems, and traffic safety. 